\title{
Active uptake of sodium in the gills of the hyperregulating shore crab Carcinus maenas
}

\author{
D. Siebers ${ }^{1}$, Č. Lucu ${ }^{2}$, A. Winkler ${ }^{1}$, L. Dalla Venezia ${ }^{3} \&$ H. Wille ${ }^{1}$ \\ ${ }^{2}$ Biologische Anstalt Helgoland (Zentrale); Notkestr. 31, D-2000 Hamburg 52 , \\ Federal Republic of Germany \\ ${ }^{2}$ Centre for Marine Research, Institute Rudjer Bošković, YU-52210 Rovinj, Yugoslavia \\ ${ }^{3}$ Istituto Di Biologia Del Mare, Riva 7 Martiri, 1364/A, I-30122 Venezia, Italy
}

\begin{abstract}
Isolated posterior gills of shore crabs, Carcinus maenas, previously acclimated for at least 1 month to brackish water of $10 \% \mathrm{~S}$, were connected with an artificial hemolymph circulation by means of thin polyethylene tubings. Gills were symmetrically perfused and bathed with $50 \%$ sea water. Transepithelial potential differences (PDs) and fluxes of sodium between medium and blood were measured under control conditions and following reductions of PDs by means of $5 \mathrm{mM}$ internal (blood side) ouabain, $0.5 \mathrm{mM}$ internal and external (bathing medium) $\mathrm{NaCN}$ or by exhaustion of energy reserves along with a prolonged perfusion period of more than $9 \mathrm{~h}$. In these experiments ${ }^{22} \mathrm{Na}$ was used as tracer. Each of the three modes of reducing transepithelial potential differences resulted in a decrease in sodium influxes from 500-1000 $\mu$ moles $\mathrm{g}^{-1} \mathrm{~h}^{-1}$ to $250-400$ $\mu$ moles $\mathrm{g}^{-1} \mathrm{~h}^{-1}$. The findings suggest that sodium influx, which normally greatly exceeds efflux, was diminished by its active component. The remaining non-inhibitable influx equals efflux values. Our findings thus indicate that efflux is completely passive, while influx has - beside a passive component of efflux magnitudes - an additional active portion which is much larger than the passive component. Since ouabain is a specific inhibitor of the Na-K-ATPase, our results confirm previous findings (Siebers et al., 1985) that the basolaterally located Na-K-ATPase generates the transepithelial potential difference in the gills, which is inside negative by about $6-12 \mathrm{mV}$. Inhibition of the active portion of sodium influx by internal ouabain along with reduced PDs suggests that transepithelial PDs generated by the branchial sodium pump are the driving force for active sodium uptake in hyperregulating brackish water crabs.
\end{abstract}

\section{INTRODUCTION}

Most marine invertebrates are stenohaline osmoconformers which are - within narrow boundaries - dependent on oceanic salinity levels. The few euryhaline species capable of temporarily or permanently inhabiting brackish water have to counteract passive influx of water and loss of salts by means of active uptake of ions. In crustaceans and fishes ion fluxes occur mainly across the gills. Brackish water invertebrates hyperregulate their body fluids with respect to the ambient medium. Only few bivalves, including Mytilus edulis, do not need to hyperregulate when inhabiting brackish water. Their tissues are tolerant to considerable dilution. Finally, all freshwater animals, without exception, are effective hyperregulators.

Successful thriving of animals in brackish water and fresh water therefore depends on their capacity for active ion uptake, which proceeds against the gradient from the 
ambient water across the gills into the body fluids. Active ion transport is performed by means of ion pumps consuming ATP for energizing the uphill translocative step. Our work has in the past been devoted to the role of the sodium pump in hyperregulating shore crabs, Carcinus maenas (Siebers et al., 1982; 1983). This pump, the Na-K-ATPase, is located within the basolateral membranes of the epithelial cells in the gills of the crabs.

Using an isolated perfused gill preparation Siebers et al. (1985) demonstrated that the sodium pump generates a transepithelial potential difference (PD) between external medium and blood. This PD represents an internal electronegativity of about 6-12 $\mathrm{mV}$. The potential difference equals the sodium pump in all properties investigated, among them dependence on biological energy (ATP), salinity and $\mathrm{Na}$ concentration, susceptibility to depletion of internal (blood side) $\mathrm{K}$ and to the addition of internal ouabain. These findings led to the suggestion that the internal negativity generated by the sodium pump represents an active transport potential which is the driving force for uphill movement of $\mathrm{Na}$.

It is the aim of this publication to present experimental evidence for our assumption of a direct relation between the transepithelial potential differences and fluxes of sodium. If, as we hypothesize, the potential difference is the driving force for active uptake of $\mathrm{Na}$, then all procedures reducing the magnitude of this PD should result in a reduction of active influx of $\mathrm{Na}$. As effectors of $\mathrm{PD}$ we employed internal ouabain and $\mathrm{CN}^{-}$ions and made use of decreases in available biological energy occurring along with the proceeding duration of the experimental time. The PD is adversely affected by symmetrically applied $\mathrm{CN}^{-}$ions in a concentration-dependent mode (Winkler, personal communication).

\section{MATERIALS AND METHODS}

\section{Experimental animals}

Male and female shore crabs, Carcinus maenas, were obtained from fishermen in Kiel, FRG (Baltic Sea). We used only adults with a carapace width of approx. $6 \mathrm{~cm}$. Methods of maintenance of crabs under laboratory conditions, feeding, filtering of sea water and brackish water, acclimation temperatures, salinities, and light conditions were the same as previously reported (Siebers et al., 1985).

\section{Perfusion technique}

The afferent and efferent blood vessels of excised individual posterior gills (7-9) were connected with a pump-driven artificial circulation by means of fine polyethylene tubings and perfused at a flow rate of $0.13 \mathrm{ml} \mathrm{min}^{-1}$ with $50 \%$ sea water $(445 \mathrm{mOsm} \mathrm{kg}$ $\hat{=} 200 \mathrm{mM} \mathrm{Na}$ ). Externally, as bathing medium, the same diluted sea water was employed. Perfusion and bathing medium were connected to $\mathrm{Ag} / \mathrm{AgCl}$ reference electrodes (model 373, Ingold, Frankfurt, FRG) immersed in satured $\mathrm{KCl}$ by means of agar bridges $(3 \%$ agar in $3 \mathrm{M} \mathrm{KCl})$. Transepithelial potential differences which are spontaneously generated by the gill epithelium between external (bathing) and internal (perfusion) medium were measured with a sensitive millivoltmeter (Beckman SelectIon 5000) 
connected with the electrodes (for further details of PD measurements see Siebers et al., 1985).

Using the same solution symmetrically on the external and the internal side of the epithelial cell is the method to be chosen when the generation of asymmetry (diffusional, passive) PDs is to be avoided and only symmetry PDs (active transport potentials) are to be measured. It was shown by Siebers et al. (1985) that $50 \%$ sea water can be successfully used as a perfusing medium instead of crab Ringer solution, and that addition of nutrients (amino acids, glucose) and $\mathrm{NH}_{4} \mathrm{Cl}$ is not necessary because the gill can generate PDs over hours utilizing its own energy sources.

\section{Sodium fluxes}

Sodium fluxes were measured by means of ${ }^{22} \mathrm{Na}$ (Amersham) used as a tracer at the specific activity of $1 \mathrm{mCi}$ per mole $\mathrm{Na}$. In order to measure influx, labeled sodium was applied externally, and occurrence of ${ }^{22} \mathrm{Na}$ was quantitatively monitored over 4 subsequent periods of $10 \mathrm{~min}$ internally, e. $\mathrm{g}$. at the exit of the tube inserted into the efferent vessel of the gill.

After measuring influx, ${ }^{22} \mathrm{Na}$ was changed from the bathing to the perfusing medium. The gill was flushed under the new conditions for $20 \mathrm{~min}$ prior to measuring efflux. When efflux was to be measured ${ }^{22} \mathrm{Na}$ was monitored during the same intervals in the bathing medium. This relatively long procedure of measuring influx and efflux for 40 min each was performed under control conditions and after affecting the PD by means of inhibitors.

The fluxes of $\mathrm{Na}$ were calculated according to the following equation:

$$
\text { Na-flux }\left[\mu \text { moles }(\mathrm{g} \text { fresh weight })^{-1} \cdot \mathrm{h}^{-1}\right]=\frac{\mathrm{cpm} \cdot \mathrm{c}_{\mathrm{Na}} \cdot 6 \cdot 10^{3}}{\left[\mathrm{cpm} \cdot(\mathrm{ml} \mathrm{standard})^{-1}\right] \cdot \text { fresh weight }}
$$

where $\mathrm{cpm}=$ radioactivity of ${ }^{22} \mathrm{Na}$ being transported from external to internal medium (influx) or vice versa (efflux) within the experimental period of $10 \mathrm{~min} ; \mathrm{C}_{\mathrm{Na}}=$ concentration of unlabeled $\mathrm{Na}(\mathrm{mM})$ in brackish water of $445 \mathrm{mOsm} \mathrm{kg}^{-1}$, amounting to $200 \mathrm{mM}$ $\mathrm{Na}$ (Winkler et al., 1982); $\mathrm{cpm}\left(\mathrm{ml}\right.$ standard) ${ }^{-1}=$ radioactivity of ${ }^{22} \mathrm{Na}$ per $\mathrm{ml} 50 \%$ sea water, applied externally (influx) or internally (efflux); and fresh weight $=$ weight of the gill (mg) after careful blotting between paper towels.

\section{RESULTS}

\section{Effects of ouabain}

Gill 7 of a shore crab, C. maenas, previously acclimated to brackish water of $10 \% \mathrm{~S}$ for at least 1 month was perfused and bathed with $50 \%$ sea water $\left(445 \mathrm{mOsm} \mathrm{kg}{ }^{-1}\right)$. As shown in Figure 1, a relatively stable transepithelial PD developed, amounting to about $-7 \mathrm{mV}$ (hemolymph side negative). When, after $2 \mathrm{~h}$ run under control conditions, $5 \mathrm{mM}$ ouabain was added to the perfusing medium, PD increased to about $-1 \mathrm{mV}$ within approx. $1.5 \mathrm{~h}$. The increase was characterized by a faster initial and a slower subsequent phase.

The periods of measuring influx and efflux of $\mathrm{Na}$ under control conditions and 


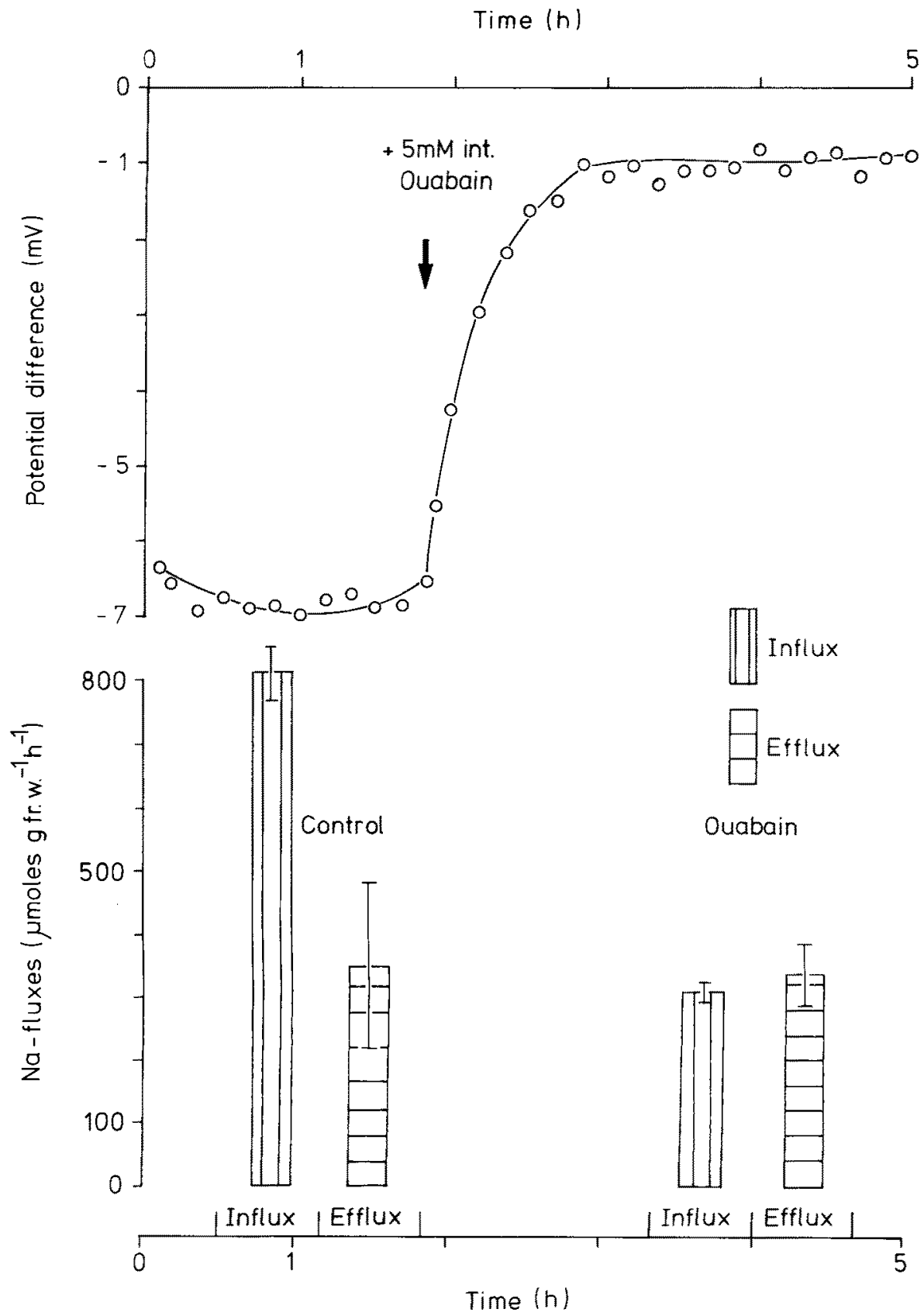

Fig. 1. Carcinus maenas. Transepithelial potential differences and sodium fluxes in an isolated posterior gill in absence and in the presence of $5 \mathrm{mM}$ internal ouabain. Gill 7 of a crab acclimated to a salinity of $10 \%$ was perfused and bathed with $50 \%$ sea water. For tracing we used ${ }^{22} \mathrm{Na}$. Standard deviations of Na fluxes were calculated using the results of 4 subsequent measurements of $10 \mathrm{~min}$ each 
following ouabain application are indicated on the abscissa of Figure 1. Sodium influx under control conditions ( $815 \mu$ moles $g$ fresh weight $\left.{ }^{-1} \mathrm{~h}^{-1}\right)$ was much higher than efflux (350 $\mu$ moles $\left.\mathrm{g}^{-1} \mathrm{~h}^{-1}\right)$. Internally applied ouabain affected only the influx of sodium. reducing it to efflux values. Rates of efflux remained unaffected by ouabain. Essentially, during ouabain treatment influx equalled efflux. The data on PDs and Na fluxes shown in Figure 1 refer to results obtained from an individual gill. Table 1 shows the results in terms of means and standard deviations obtained from a sample size of 6 gills. These results confirm the findings shown for a single gill in Figure 1.

Table 1. Carcinus maenas. Transepithelial potential differences (PD) and Na-fluxes in isolated, perfused, posterior gills (7) in absence (control) and in the presence of $5 \mathrm{mM}$ internal ouabain. The crabs were acclimated to a salinity of $10 \% \mathrm{~S}$ for more than 1 month. During perfusion the gills were symmetrically exposed to $50 \%$ sea water used as perfusing and bathing medium. Data represent means and standard deviations obtained from a sample size of 6 gills. For time schedules of flux measurements see Figure 1

\begin{tabular}{|ccc|}
\hline $\begin{array}{c}\text { Experimental } \\
\text { conditions }\end{array}$ & $\begin{array}{c}\text { Potential differences } \\
(\mathrm{mV})\end{array}$ & $\begin{array}{c}\text { Na-fluxes } \\
\left(\mu \text { moles } \mathrm{g} \text { fr. } \mathrm{w}^{-1} \mathrm{~h}^{-1}\right)\end{array}$ \\
\hline Influx control & $-6.5 \pm 0.4$ & $686 \pm 109$ \\
Efflux control & $-6.3 \pm 0.3$ & $366 \pm 30$ \\
Influx ouabain & $-1.2 \pm 0.2$ & $368 \pm 45$ \\
Efflux ouabain & $-1.1 \pm 0.3$ & $355 \pm 53$ \\
\hline
\end{tabular}

\section{Effects of $\mathrm{NaCN}$}

Perfusing and bathing posterior gills with $50 \%$ sea water resulted in a PD of approx. $-5.5 \mathrm{mV}$ (Fig. 2). Symmetrical application of $0.5 \mathrm{mM} \mathrm{NaCN}$ instantly abolished this internal negativity. PDs increased to about $-0.7 \mathrm{mV}$. Correspondingly, influxes of $\mathrm{Na}$ were reduced from 515 to $230 \mu$ moles $g$ fresh weight ${ }^{-1} \mathrm{~h}^{-1}$.

\section{Exhaustion of energy reserves}

After having nearly completely abolished the transepithelial potential difference across the gill epithelium by ouabain or $\mathrm{NaCN}$ in the 2 preceding experiments, an attempt was made to affect the PD without application of a chemical agent. We carried out a long experiment during which the PD steadily increased from $-5 \mathrm{mV}$ towards $0 \mathrm{mV}$, reaching $-2.7 \mathrm{mV}$ after $9 \mathrm{~h}$ (Fig. 3). Using fluxes of ${ }^{22} \mathrm{Na}$ and the concentration of unlabeled $\mathrm{Na}$, in- and efflux of total $\mathrm{Na}$ were calculated (see "Materials and Methods"). While Na influx decreased from about $980 \mu$ moles $g$ fresh weight ${ }^{-1} \mathrm{~h}^{-1}$ at the beginning of the experiment to about $550 \mu$ moles $\mathrm{g}^{-1} \mathrm{~h}^{-1}$ at the end, effluxes remained virtually unchanged. 

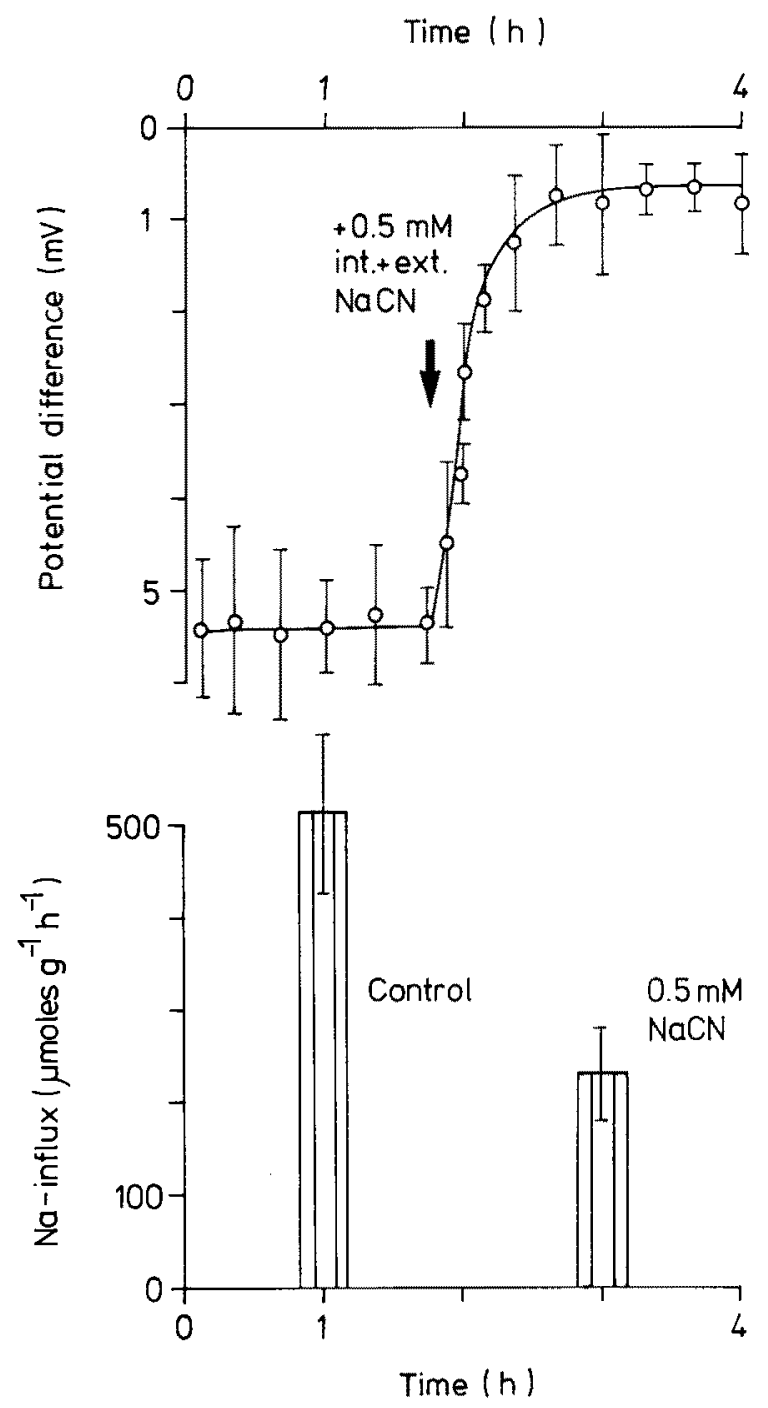

Fig. 2. Carcinus maenas. Transepithelial potential differences and influxes of sodium in isolated posterior gills in absence and in the presence of symmetrically applied $0.5 \mathrm{mM} \mathrm{NaCN}$. Gill 7 of crabs acclimated to a salinity of $10 \%$ was perfused and bathed with $50 \%$ sea water. For tracing we used ${ }^{22} \mathrm{Na}$. Data represent means \pm standard deviations (vertical bars) obtained from a sample size of 5 gills. For time schedules of influx measurements see "Materials and Methods"

\section{DISCUSSION}

\section{Active uptake of sodium}

The remarkable longevity of the gill allows measurements of PDs and Na-fluxes over extended experimental periods of ca. $9 \mathrm{~h}$ (Fig. 3) or more. Considering all three experiments (Fig. 1-3) as a whole, it becomes evident that influxes of $\mathrm{Na}$ under control 
Time $(h)$
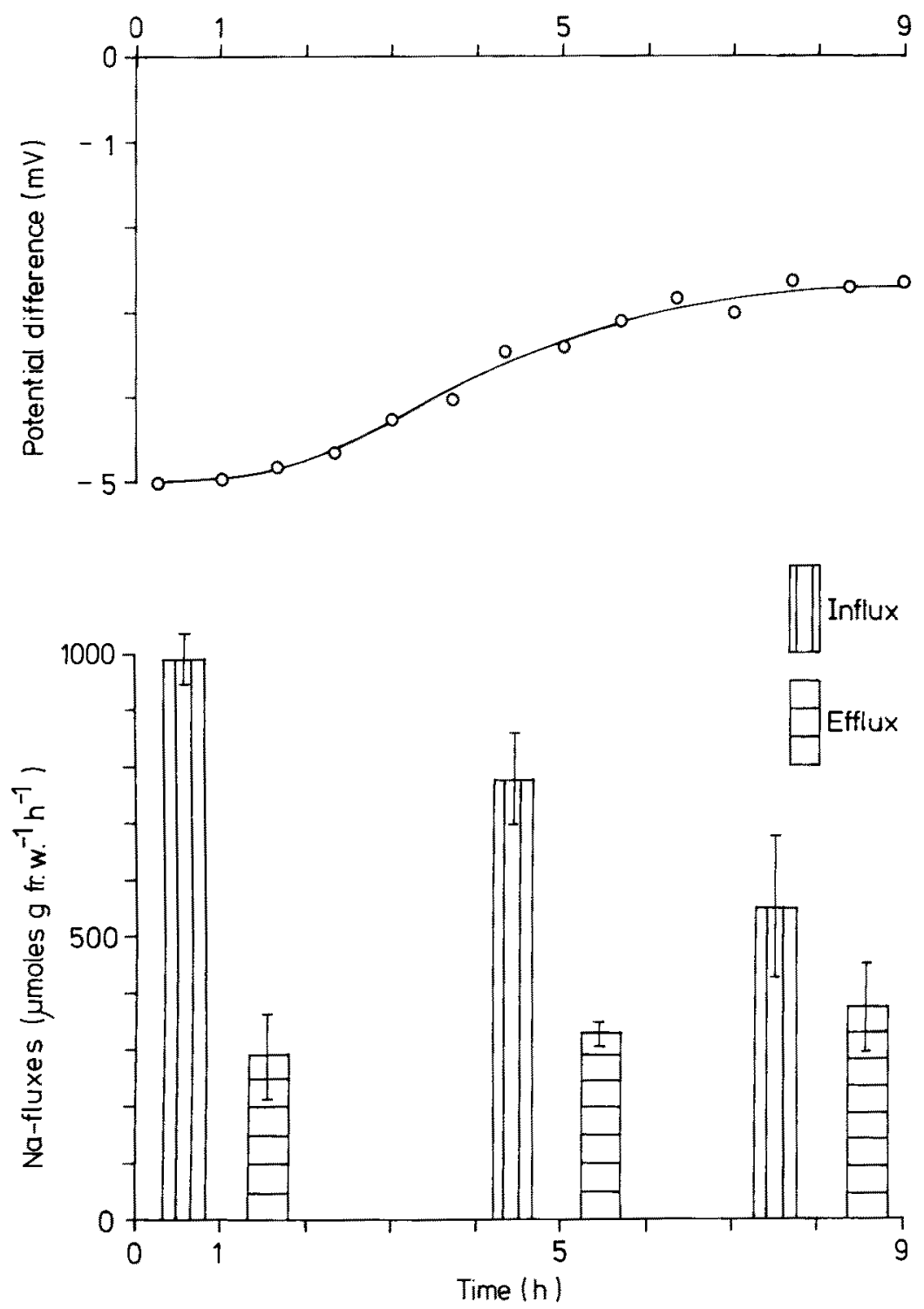

Fig. 3. Carcinus maenas. Transepithelial potential differences and sodium fluxes in an isolated posterior gill over an extended experimental period. Gill 7 of a crab acclimated to a salinity of $10 \%$ was perfused and bathed with $50 \%$ sea water. For tracing we used ${ }^{22} \mathrm{Na}$. Standard deviations of $\mathrm{Na}$ fluxes were obtained from 4 subsequent measurements of 10 min each 
conditions (500-1000 mmoles $\mathrm{g}^{-1} \mathbf{h}^{-1}$ ) were always much higher than effluxes (250-400 mmoles $\mathrm{g}^{-1} \mathrm{~h}^{-1}$ ). We consider effluxes as the permanently proceeding passive outward movement of sodium which is accompanied by a passive, diffusional influx of the same magnitude. The potential difference resulting from equal in- and outflux of $\mathrm{Na}$ is zero. That proportion of influx which significantly exceeds efflux is the active component of the total influx. Only this active influx component is coupled to the potential differences measured. Efflux thus consists of one (passive) component and influx of a passive and an additional active portion, where both passive components are equal. The active component of influx is usually much larger - between 60 and $80 \%$ of the total influx - than the passive portion.

The results presented indicate that inhibition of Na-fluxes by ouabain, $\mathrm{CN}^{-}$ions or as a result of exhausted energy reserves only affected the active portion of the influx, reducing it to the non-inhibitable passive component. Effluxes were not affected.

\section{Localization of the sodium pump}

In order to demonstrate the participation of the Na-K-ATPase in Na-uptake of hyperregulating brackish water invertebrates, ouabain has in the past been applied in vivo. Mangum et al. (1979) kept clams, Rangia cuneata, in very dilute brackish water media of $1-2 \% \mathrm{~S}$, where they effectively hyperregulate. Addition of $10^{-4} \mathrm{M}$ ouabain to the ambient medium reduced blood $\mathrm{NaCl}$ by one half. Ouabain, as the authors suppose, permeated from the medium to the blood, thus affecting the $\mathrm{NaCl}$ ratio between medium and blood at the basal side.

Ouabain reduced serum osmolalities in crabs, Carcinus maenas, kept in brackish water of 9-10\% $\mathrm{S}$, only when injected into the hemolymph ( 1 and $5 \cdot 10^{-5} \mathrm{M}$ ) but had no effect when dissolved in ambient water $\left(10^{-4} \mathrm{M}\right)$ (Siebers et al., 1982). This finding supports the assumption that the sodium pump, which is specifically inhibited by the drug, is located at the basal side of the epithelial cells.

Pèqueux \& Gilles (1981) perfused gills of the Chinese crab, Eriocheir sinensis, acclimated to fresh water, using a technique essentially equal to ours. Though not explicitly communicated we suppose that these authors - in their experiments with ouabain - applied asymmetry conditions with respect to salinities and sodium concentrations in perfusion and bathing salines. They found that in posterior gills of $E$. sinensis $10^{-3} \mathrm{M}$ ouabain inhibited Na-influx only if applied outside; addition of the drug to the perfusion saline had no significant effect. Pèqueux \& Gilles therefore consider the localization of the Na-pump on the external side of the epithelium. This result is in contrast to our findings with respect to the localization of the Na-pump in shore crab gills. In Carcinus, $5 \mathrm{mM}$ internal ouabain dramatically reduced the negative $\mathrm{PD}$ and greatly decreased Na-influx (Fig. 1), but was without significant effect on PD when applied externally. Our findings closely correspond to the results obtained by Drews (1985) using isolated, perfused posterior gills of fiddler crabs, Uca tangeri. Ouabain $\left(10^{-3}\right.$ M) was without effect on PD when applied externally but significantly $(n=7)$ reduced transepithelial PDs in a reversible mode by one half when applied on the hemolymph side. Drews regarded this result as a convincing argument to assume the presence of ouabain-sensitive Na-K-ATPase in UCa gills on the basal side of the epithelial cells. 


\section{Relation between Na-pump, PD, and active influx of $\mathrm{Na}$}

Up to about 1984, much experimental evidence had been collected indicating that in aquatic metazoans, when exposed to dilute media, the branchial Na-K-ATPase plays a central role in hyperregulation of the body fluids (for review articles see Towle, 1981; $1984 \mathrm{a}, \mathrm{b})$. This evidence was mainly based on changes in the concentration of Na-pump molecules within the gill tissues as a result of altered ambient salinities. Data on activities and localization of Na-K-ATPase were mainly obtained by use of enzymatic and ultrastructural procedures.

A detailed understanding of the mode of functioning of the Na-K-ATPase in the process of uphill ion translocation by the gill tissues was, however, still lacking. It was proposed by Siebers et al. (1985), using isolated, perfused gill preparations, that the Napump generates a transepithelial potential difference, which is inside negative by about . 6-12 $\mathrm{mV}$ and represents the driving force for active Na uptake.

This conclusion was deduced from the finding that internally applied ouabain adversely affected the potential differences measured by nearly totally abolishing them. It is known that ouabain specifically inhibits the Na-K-ATPase. In this context we have shown (Siebers et al., 1985) that the PD inhibited by ouabain fully recovered upon omission of the drug and that consequently no lasting damage had remained. That the PDs measured may also quantitatively account for establishing and maintaining the external/internal concentration difference of $\mathrm{Na}$ in a hyperregulating crab was shown by means of the Nernst equation. We found that a PD of $-13.7 \mathrm{mV}$ would be sufficient to hyperregulate blood sodium by $135 \mathrm{mM}$ in relation to an ambient level of $200 \mathrm{mM} \mathrm{Na}$ (15\% S) resulting in an internal concentration of $335 \mathrm{mM}$ (Siebers et al., 1985).

The present work confirms these previously published conclusions by direct measurements of Na-fluxes in relation to the respective potential differences. Especially the finding that internally applied ouabain nearly complety inhibited the active component of the Na influx, besides the known effects of abolishing the PDs, strongly suggests that the transepithelial potential differences generated by the branchial Na-K-ATPase represent the driving forces for active uptake of $\mathrm{Na}$ in hyperregulating shore crabs.

These conclusions are furthermore confirmed by the results shown in Figures 2 and 3. In both experiments the PD was adversely affected by employment of $\mathrm{CN}^{-}$ions and non-availability of biological energy as a result of a prolonged experimental period. Each time, the influx of $\mathrm{Na}$ was reduced to levels close to efflux values. These findings show that the active portions of the influxes of total Na had been greatly inhibited along with considerably reduced or lacking potential differences.

Acknowledgements. This research is part of the program 'Stoffwechsel unter Extrembedingungen' of the Deutsche Forschungsgemeinschaft, whose grant Si 295/1-4 is gratefully acknowledged. We express our thanks to Professor Dr. K.-J. Ullrich and Dr. R. Greger (Max-Planck-Institut für Biophysik, Frankfurt/Main) for their interest in our work, discussion of results and helpful advice in experimental procedures. D. Siebers and C. Lucu gratefully accepted travel support from the Germany/Yugoslavia cooperation program.

\section{LITERATURE CITED}

Drews, G., 1985. Elektrophysiologische und biochemische Untersuchungen zur osmoregulatorischen Fähigkeit und zur Salzaufnahme über das Kiemenepithel von Uca tangeri. Diss., Freie Univ. Berlin, $139 \mathrm{pp}$. 
Mangum, C. P., Henry, R. P. \& Simpson, D. M., 1979. The effect of ouabain on blood $\mathrm{NaCl}$ in the osmoregulating clam Rangia cuneata. - J. exp. Zool. 207, 329-335.

Pèqueux, A. \& Gilles, R., 1981. $\mathrm{Na}^{+}$fluxes across isolated perfused gills of the chinese crab Eriocheir sinensis. - J. exp. Biol. 92, 173-186.

Siebers, D., Leweck, K., Markus, H. \& Winkler, A., 1982. Sodium regulation in the shore crab Carcinus maenas as related to ambient salinity. -- Mar. Biol. 69, 37-43.

Siebers, D., Winkler, A., Leweck, K. \& Madian, A., 1983. Regulation of sodium in the shore crab Carcinus maenas, adapted to environments of constant and changing salinities. - Helgoländer Meeresunters. 36, 303-312.

Siebers, D., Winkler, A., Lucu, C., Thedens, G, \& Weichart, D., 1985. Na-K-ATPase generates an active transport potential in the gills of the hyperregulating shore crab Carcinus maenas. - Mar. Biol. 87, 185-192.

Towle, D. W., 1981. Role of $\mathrm{Na}^{+}+\mathrm{K}^{+}-$ATPase in ionic regulation by marine and estuarine animals. - Mar. Biol. Lett. 2, $107-121$.

Towle, D. W., 1984a. Regulatory functions of $\mathrm{Na}^{+}+\mathrm{K}^{+}-$ATPase in marine and estuarine animals. In: Osmoregulation in estuarine and marine animals. Ed. by A. Pèqueux \& L. Bolis. Springer, Berlin, 157-170.

Towle, D. W., 1984b. Membrane-bound ATPases in arthropod ion-transporting tissues. - Am. Zool. 24, 177-185.

Winkler, A., Siebers, D. \& Leweck, K., 1982. Zur Bestimmung von Natrium im Meerwasser mit ionensensitiven Elektroden. - GIT Fachz. Lab. 26, 228-229. 